\title{
DNA methylation profiling in the thalamus and hippocampus of postnatal malnourished mice, including effects related to long-term potentiation
}

Xiaoling Weng ${ }^{1 \dagger}$, Daizhan Zhou ${ }^{2 \dagger}$, Fatao Liu ${ }^{3 \dagger}$, Hong Zhang ${ }^{1}$, Junyi Ye ${ }^{1}$, Zhou Zhang ${ }^{2}$, Di Zhang ${ }^{2}$, Yinan Wang ${ }^{2}$, Liming Tao ${ }^{3}$, Lan Cao ${ }^{1}$, Mengyuan Kan ${ }^{3}$, Ting Wang ${ }^{3}$, Guoyin Feng ${ }^{2,3}$, Xiaolan Qin², Jihui Sun ${ }^{4}$, Lin He 1,23,6* and Yun Liu' ${ }^{1,5^{*}}$

\begin{abstract}
Background: DNA methylation has been viewed as the most highly characterized epigenetic mark for genome regulation and development. Postnatal brains appear to exhibit stimulus-induced methylation changes because of factors such as environment, lifestyle, and diet (nutrition). The purpose of this study was to examine how extensively the brain DNA methylome is regulated by nutrition in early life.

Results: By quantifying the total amount of 5-methylcytosine $(5 \mathrm{mC})$ in the thalamus and the hippocampus of postnatal malnourished mice and normal mice, we found the two regions showed differences in global DNA methylation status. The methylation level in the thalamus was much higher than that in the hippocampus. Then, we used a next-generation sequencing (NGS)-based method (MSCC) to detect the whole genome methylation of the two regions in malnourished mice and normal mice. Notably, we found that in the thalamus, 500 discriminable variations existed and that approximately $60 \%$ were related to neuronal development or psychiatric diseases.

Pathway analyses of the corresponding genes highlighted changes for 9 genes related to long-term potentiation (5.3-fold enrichment, $\mathrm{P}=0.033$ ).

Conclusions: Our findings may help to indicate the genome-wide DNA methylation status of different brain regions and the effects of malnutrition on brain DNA methylation. The results also indicate that postnatal malnutrition may increase the risk of psychiatric disorders.
\end{abstract}

Keywords: Malnutrition, Thalamus, Hippocampus, Mouse model, Global DNA methylation status, Whole genome methylation sequencing, Long-term potentiation, Psychiatric disorders

\section{Background}

Nutrition represents one of the major important variables that play crucial roles in the maturation and functional development of the central nervous system (CNS) [1]. Malnutrition exerts its effects during the brain growth spurt period, and it results in a variety of brain dysfunctions [2].

\footnotetext{
* Correspondence: helin@bio-x.cn; superliuyun@gmail.com

${ }^{\dagger}$ Equal contributors

'Institutes of Biomedical Sciences, Fudan University, Shanghai 200032, PR China

${ }^{2}$ Bio-X Center, Key Laboratory for the Genetics of Developmental and Neuropsychiatric Disorders, Ministry of Education, Shanghai Jiao Tong University, Shanghai 200030, PR China

Full list of author information is available at the end of the article
}

Growth deficits due to malnutrition in childhood increase the incidence of infectious diseases and lead to alterations in CNS function, which have been shown to delay psychomotor development [3]. Thus, understanding the pathological effects of malnutrition will provide critical insights into the neurodevelopmental process.

DNA methylation is among the best studied epigenetic modifications and is essential to mammalian development [4]. Specifically, the methylation of cytosine at CpG dinucleotides is an important regulatory modification of the genome [5]. Many epigenetic studies on DNA methylation

\section{() Biomed Central}

(c) 2014 Weng et al.; licensee BioMed Central Ltd. This is an Open Access article distributed under the terms of the Creative Commons Attribution License (http://creativecommons.org/licenses/by/2.0), which permits unrestricted use, distribution, and reproduction in any medium, provided the original work is properly credited. 
have revealed that malnutrition during the perinatal period is highly correlated with abnormal neurodevelopment [6].

Studies of epigenetic modifications benefit substantially from improved next-generation sequencing methods, and recent technologies make it possible for accurate and largescale CpG methylation profiling [7]. Methyl-sensitive cut counting (MSCC) is a NGS method used to profile the whole DNA methylome. The MSCC genome-scale analysis is based on the concept that locations of CCGGs largely reflect the distributions of all CpGs in the mouse genome [8].

In our study, we utilized a mouse model of male mice to avoid sex differences, as sexual dimorphism and sexual differentiation have been thought to underlie the sexual development of the brain and other organs, which could impact lifelong functions [9]. First, we detected the global DNA methylation status in the thalamus and the hippocampus of postnatal malnourished mice and normal mice. Because the two regions showed differences in global DNA methylation status, we employed MSCC to investigate DNA methylation to determine how extensively the two brain DNA methylomes were regulated by nutrition in early life.

\section{Methods}

\section{Mouse husbandry}

All animal care and use procedures were in accordance with the guidelines of the Institutional Animal Care and Use Committee for Nutritional Sciences, Shanghai Institutes for Biological Sciences, Chinese Academy of Sciences. The parental mice in this study were purchased from Shanghai Laboratory Animal Co. Ltd. (SLAC, Shanghai, China) and housed under controlled conditions of $12 \mathrm{~h} \mathrm{light} / 12 \mathrm{~h}$ dark cycle at $23 \pm 2^{\circ} \mathrm{C}$ and $35 \pm$ $5 \%$ humidity. The parental mice had been raised for at least two generations on a control diet to attempt to minimize any trans-generational effects. The male offspring mice were weaned from the mothers at 20 days of age and were divided randomly into two groups $(\mathrm{n}=7$ in control group, $\mathrm{n}=5$ in famine group): the control group was given a standard diet (D12450B), and the famine group was fed with half of a low-protein diet (D06022301) [10]. After 6 weeks of artificial feeding, offspring mice were euthanized (the weights of the offspring mice were measured every week from weaning); the entire thalamus and hippocampus were dissected out and immediately stored at $-80^{\circ} \mathrm{C}$.

\section{DNA preparation}

Genomic DNA was isolated from $\geq 25 \mathrm{mg}$ samples (thalamus and hippocampus of malnourished mice and normal mice) using the QIAamp DNA Mini Kit following the standard protocol (QIAGEN, Hilden, Germany). To ensure the sample quality, a Thermo NanoDrop 2000 (Thermo, Wilmington, USA) was used to detect $260 / 280 \mathrm{~nm} \mathrm{UV}$ absorbance ratios, and concentrations were determined with a Qubit 2.0 fluorometer (Life Technologies, Carlsbad, CA). DNA length was determined by an Agilent 2100 Bioanalyzer (Agilent, Santa Clara, CA) to ensure the integrity. We constructed two MSCC libraries for each of our two brain tissues that contained pooled DNA from the control group and the famine group. Pooled DNA was used to increase the sample concentration and diminish micro-dissection variations.

\section{Global DNA methylation status detection and calculation} The MethylFlash ${ }^{\mathrm{Tm}}$ Methylated DNA Quantification Kit (Fluorometric) was used to detect the total amount of $5 \mathrm{mC}$ in the thalamus and hippocampus according to the manufacturer's instructions (Epigentek, Farmingdale, NY). Relative fluorescence units (RFU) at $530_{\mathrm{EX}} / 590_{\mathrm{EM}} \mathrm{nm}$ were measured using a SpectraMax M5 (Molecular Devices, CA, USA) to calculate the global methylation status.

\section{MSCC library construction}

To detect cytosine methylation, MSCC utilized the restriction enzymes HpaII and MspI, which preferentially cut DNA based on its methylation status. Although both enzymes recognized the same restriction site CCGG, $H p a I I$ was a methylation-sensitive enzyme, while $M s p \mathrm{I}$ was insensitive to methylation sites. Adaptors A and B were also created for MSCC and were synthesized by Sangon Biotech (Shanghai, China). Adaptor A contained a 5' MmeI recognition site and a 5' CG overhang, while adaptor B had a 3' NN overhang. Both adapters also contained end sequences required for Illumina library construction. Then, we constructed a HpaII library and an Inverse library for our study. To correct the error during the experiment of the HpaII library and the Inverse library, we combined standard DNA in the two libraries that contained the same known methylated or no methylated sequences. Further details are provided in the Additional file 1: Supplementary Method.

\section{Library sequencing and mapping}

Before sequencing, we used a Perl script to extract $20 \mathrm{bp}$ upstream and $20 \mathrm{bp}$ downstream of every CCGG site from the whole mouse genome (mm9). Based on the UCSC Refseq database, we added annotation to these short sequences and established a CCGG sequence database. The two libraries were sequenced on the Hiseq2000 depth sequencing system (Illumina, San Diego, California). After sequencing, the HpaII library and the Inverse library data from the Hiseq2000 depth sequencing system (bcl document) were transformed into a fastq file using CASAVA software. The fastq file data were mapped to the CCGG sequence database that we constructed using MOM software. We then analyzed the number of reads in the same CCGG position to calculate the degree of methylation 
Table 1 Mouse weights from the beginning of artificial feeding

\begin{tabular}{lccccccc}
\hline Group & \multicolumn{7}{c}{ Weight (g)/week } \\
\cline { 2 - 8 } & $\mathbf{0}$ & $\mathbf{1}$ & $\mathbf{2}$ & $\mathbf{3}$ & $\mathbf{4}$ & $\mathbf{5}$ & $\mathbf{6}$ \\
\hline Control & $8.69 \pm 0.32$ & $19.06 \pm 0.85$ & $21.57 \pm 1.21$ & $23.29 \pm 1.08$ & $24.53 \pm 1.57$ & $25.51 \pm 2.02$ & $26.04 \pm 1.87$ \\
Famine* & $8.69 \pm 0.27$ & $8.82 \pm 0.77$ & $10.28 \pm 0.44$ & $12.46 \pm 0.50$ & $13.32 \pm 0.68$ & $13.02 \pm 0.94$ & $11.45 \pm 0.78$ \\
\hline
\end{tabular}

${ }^{*} \mathrm{P}<0.05$, compared with the control group.

of each site. Standard DNA in each library was used to normalize the counts before estimating the methylation level, according to the method in Guo et al. [8].

\section{Statistical analysis}

Student's $t$-tests were used to determine the differences in mouse weights and thalamus and hippocampus methylation levels between the control group and the famine group. For the MSCC data, we constructed a 200-bp non-overlapping windows profiling of the whole genome. Windows that involved more than $3 \mathrm{CpG}$ sites sequenced were used for the subsequent analysis. For each of the 200-bp windows, we conducted Fisher exact tests to find different methylated regions (DMRs) with statistical significance $(\mathrm{P}<0.05)$ and different levels of methylation changes ( $\triangle \mathrm{MSCC}$, either increase or decrease) $>25 \%$. A P value $<0.05$ was considered significant in these analyses.

\section{Pathway classification and enrichment analysis}

Pathway analyses were performed using the Database for Annotation, Visualization and Integrated Discovery (DAVID, http://david.abcc.ncifcrf.gov/) [11]. Pathway classification within DAVID used the Kyoto Encyclopedia of Genes and Genomes database (KEGG, http://www.genome.jp/kegg/pathway.html) and PANTHER (http://www. pantherdb.org/pathway/). Enrichment statistics were adjusted by Benjamini correction.

\section{Results \\ Weight}

The weights of the offspring male mice are shown in Table 1. Data are presented as the mean \pm standard deviation (SD). As determined using Student's $t$-test, the famine group weighed less and the weights were significantly different from the control group $(\mathrm{p}<0.05)$. During feeding, the famine group displayed the phenomena of mania and hyperactivity.

\section{Total $5 \mathrm{mc}$ amount in the thalamus and hippocampus}

The global DNA methylation status in the thalamus and the hippocampus of postnatal malnourished mice and normal mice is shown in Figure 1. The global DNA methylation status in the thalamus was significantly higher than that of the hippocampus. In both the thalamus and the hippocampus, the control group had a higher total $5 \mathrm{mc}$ amount than the famine group.

\section{DNA methylome in the thalamus and hippocampus}

The reads obtained from our libraries after MSCC whole genome methylation sequencing are shown in Table 2 . After excluding MSCC sites with low sequencing depth, we obtained the DNA methylation profile of the thalamus (Additional file 2: Table S1) and the hippocampus (Additional file 3: Table S2). The overall methylation levels of all CCGG sites in the two tissues are shown in Figure 2. The CCGG methylation level of the hippocampus was also lower than that of the thalamus as the global DNA methylation status. The methylation differences between the famine and control groups or the thalamus and hippocampus were statistically significant $(\mathrm{P}<0.001)$.

In addition, we also showed the methylation level in internal, shore and external CGIs of the thalamus and the hippocampus (Additional file 1: Figure S1a and S1b). In the two groups of both tissues, the level of methylation in the internal of the $\mathrm{CpG}$ islands was lower than that of the external of the CpG islands. Furthermore, the famine group had a lower methylation level than the control group at the external of the CpG islands, whereas it was hypermethylated in the internal of the CpG islands in both brain regions. The whole genome methylation pattern showed that the methylation level near the transcription initiation site (TSS) was lower than any other position (Additional file 1: Figure S2).

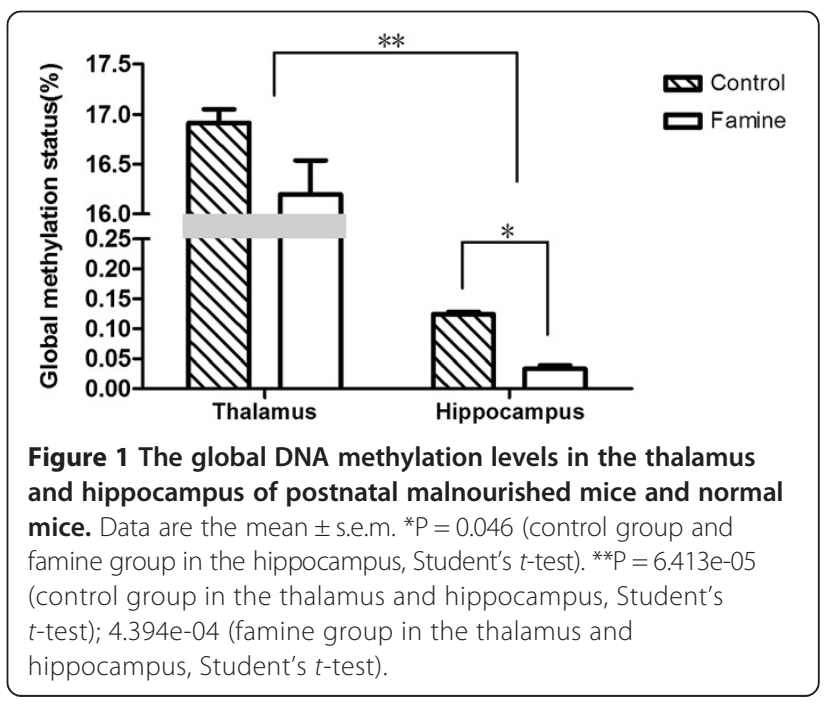


Table 2 MSCC Illumina sequencing statistics of the thalamus and hippocampus

\begin{tabular}{llllll}
\hline Library name & & $\begin{array}{l}\text { Number of reads with } \\
\text { appropriate adaptors }\end{array}$ & $\begin{array}{l}\text { Number of mapped } \\
\text { reads (percentage) }\end{array}$ & $\begin{array}{l}\text { Number of CCGG sites } \\
\text { seen at least once }\end{array}$ & $\begin{array}{l}\text { Average number of } \\
\text { reads per CCGG site }\end{array}$ \\
\hline Thalamus & Control-Hpall & 39239224 & $31413443(80.0)$ & 1034841 & 30.4 \\
& Control-Inverse & 35769649 & $20466887(57.2)$ & 1118555 & 18.3 \\
& Famine-Hpall & 57387236 & $46262199(80.6)$ & 1076064 & 43 \\
& Famine-Inverse & 46472846 & $27799576(59.8)$ & 1175605 & 23.6 \\
Hippocampus & Control-Hpall & 29639848 & $24301025(81.2)$ & 1060634 & 14.0 \\
& Control-Inverse & 26585724 & $15892801(59.8)$ & 1136208 & 27.0 \\
& Famine-Hpall & 37551216 & $30429853(81.0)$ & 1125683 & 21.4 \\
\hline
\end{tabular}

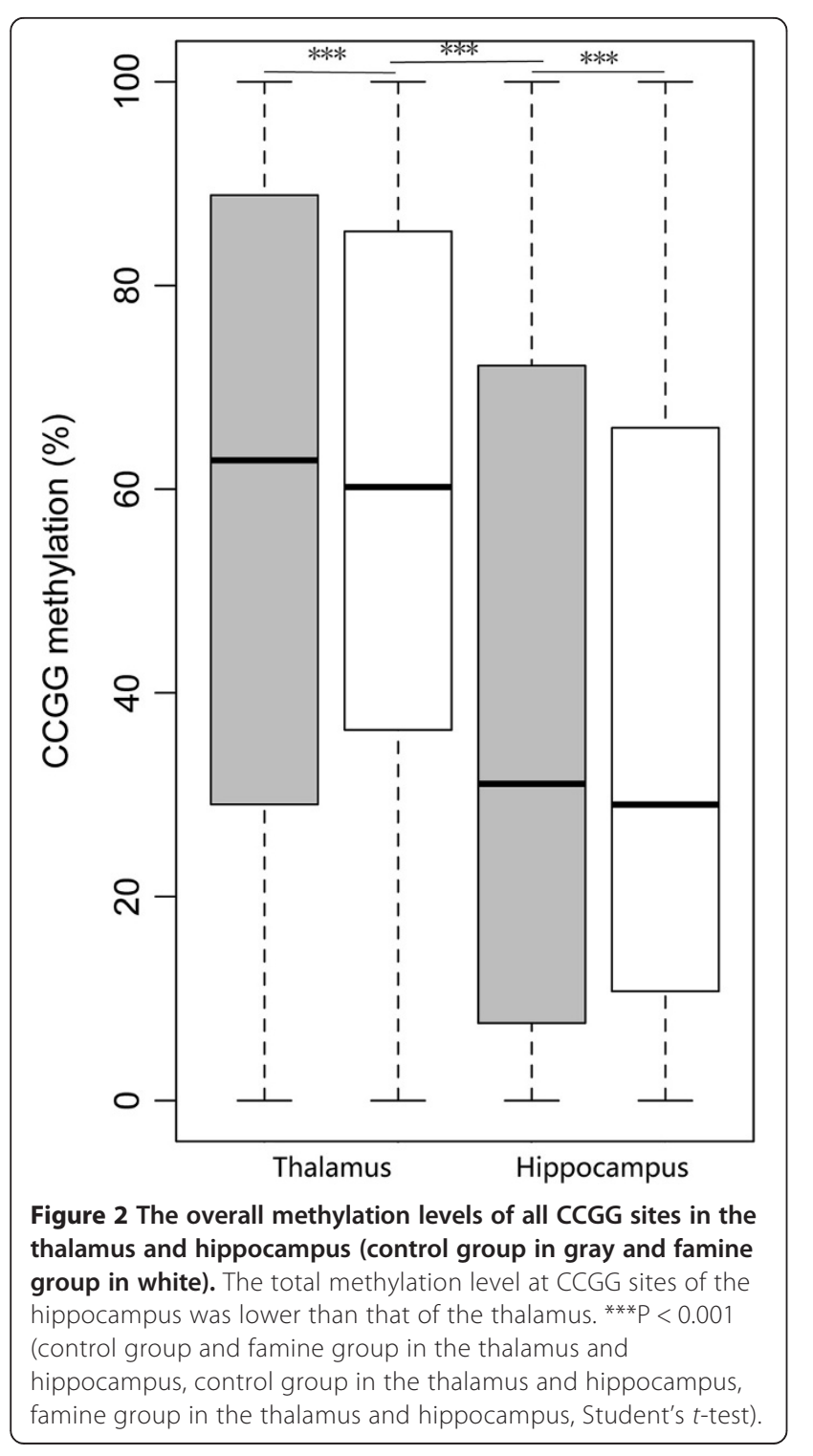

We combined the mouse thalamus gene expression data from the NCBI GEO database (GDS1490) with our MSCC thalamus data for the control group. First, we divided the database expression genes into three parts: high-expression genes, moderate-expression genes, and low-expression genes. Then, the MSCC data were integrated to the three parts of the expression genes. The relationship between the methylation level and gene expression is shown in Additional file 1: Figure S3a and S3b. The methylation level of the low-expression genes was higher at TSS but lower at the gene body than that of the high-expression genes.

Table 3 Twenty crucial genes related to psychiatric diseases among $\mathbf{5 0 0}$ selected genes of the thalamus

\begin{tabular}{|c|c|}
\hline Gene name & Related psychiatric diseases \\
\hline Slc18a2 & $\begin{array}{l}\text { Schizophrenia [12], Alzheimer's disease [13], } \\
\text { Parkinson's disease [14] }\end{array}$ \\
\hline Pi4k2b & Bipolar disorder [15] \\
\hline Prkacb & Alzheimer's disease [16] \\
\hline Gabra 1 & Schizophrenia [17] \\
\hline Bdnf & Alzheimer's disease [18], Major depression disorder [19] \\
\hline Katnb1 & Bipolar disorder [20] \\
\hline Psen 1 & Alzheimer's disease [21] \\
\hline Pde4a & Schizophrenia [22], Bipolar disorder [23] \\
\hline Lrfn5 & Autism [24] \\
\hline Ppp3ca & Alzheimer's disease $[25,26]$ \\
\hline Shank3 & Autism spectrum disorder [27,28], Bipolar disorder [29] \\
\hline $\mathrm{Clu}$ & Alzheimer's disease $[30,31]$ \\
\hline Notch4 & Bipolar disorder [32], Schizophrenia [33] \\
\hline Sult4ar & Schizophrenia [34] \\
\hline Rnf11 & Parkinson's disease [35] \\
\hline Pclo & Major depression disorder [36], Bipolar disorder [37] \\
\hline Tyro3 & Alzheimer's disease [38] \\
\hline Calm2 & Major depression disorder [39] \\
\hline Cacnalc & Schizophrenia [40-42], Bipolar disorder [43-45] \\
\hline Plcbl & Autism spectrum disorder [46], Schizophrenia [47] \\
\hline
\end{tabular}


There were 500 distinct genes in the thalamus (Additional file 4: Table S3) but none in the hippocampus, according to the results of the DMR analysis. Furthermore, all 500 selected genes obtained from the thalamus analysis of the famine group showed hypermethylation, and approximately $60 \%$ of the genes were associated with neuronal development and psychiatric diseases. The 20 crucial genes identified as being implicated in psychiatric diseases are shown in Table 3.

\section{Properties of the hypermethylated genes}

To gain mechanistic insights into the CpG modifications, we constructed our 500 gene set corresponding to biological pathways and networks underlying complex diseases using the online tool DAVID. In total, 20 pathways were matched with our gene sets, as shown in Table 4. The most highly enriched pathway, which remained significant after the adjustment for multiple hypothesis testing using the conservative Benjamini correction, was long-term potentiation (LTP, 5.3-fold enrichment, $\mathrm{P}=0.033$ ) with 9 relative genes from our study: Ppp1r1a, Ppp3r1, Raf1, Camk2b, Ppp3ca, Prkacb, Cacna1c, Plcb1, and Calm2 (Figure 3).

\section{Discussion}

In contrast to previous studies that focused mainly on the influence of maternal malnutrition on fetal neurodevelopment
$[1-3,10]$, our study provides a striking view of how the epigenetic DNA methylation landscape of the thalamus and the hippocampus in postnatal individuals is modified in response to malnourishment. We describe a genome-wide, quantitative characterization of malnourishment-induced CpG methylation changes in postnatal mice. These data may serve as a useful resource for the neuroscience community and brain science studies.

Our study demonstrated several key aspects of malnourishment-induced epigenetic DNA modifications in mice. First, the global DNA methylation status in the thalamus and the hippocampus of postnatal malnourished mice and normal mice had significant differences. This told us that the mechanism of the malnourishment-induced epigenetic DNA modifications in the thalamus was different from the hippocampus. Second, our analysis revealed specific characteristics of the genomic DNA methylation distribution in the thalamus and the hippocampus of malnourished mice and normal mice. Third, our MSCC results provided direct profiling regarding the malnourishment-induced DNA methylation changes in both the thalamus and the hippocampus. Fourth, our study provided a large number of genes that were subjected to modulation by malnourishment at the level of DNA modification. The majority of these genes were associated with neuronal occurrence and development.

Table 4 Twenty KEGG and PANTHER pathways applied to the $\mathbf{5 0 0}$ hypermethylated genes in the thalamus

\begin{tabular}{|c|c|c|c|c|c|}
\hline \multirow[t]{2}{*}{ Category } & \multirow[t]{2}{*}{ Pathway } & \multirow[t]{2}{*}{ Count } & \multicolumn{2}{|l|}{ Fold } & \multirow{2}{*}{$\frac{\text { Benjamini }}{\text { P value }}$} \\
\hline & & & Enrichment & $P$ value & \\
\hline KEGG_PATHWAY & Long-term potentiation & 9 & 5.270 & $2.58 \times 10-4$ & 0.033 \\
\hline KEGG_PATHWAY & MAPK signaling pathway & 16 & 2.475 & 0.002 & 0.108 \\
\hline PANTHER_PATHWAY & Alzheimer disease-amyloid secretase pathway & 9 & 3.872 & 0.002 & 0.147 \\
\hline KEGG_PATHWAY & Long-term depression & 7 & 3.985 & 0.008 & 0.283 \\
\hline KEGG_PATHWAY & GnRH signaling pathway & 8 & 3.380 & 0.009 & 0.250 \\
\hline KEGG_PATHWAY & Calcium signaling pathway & 11 & 2.360 & 0.017 & 0.360 \\
\hline KEGG_PATHWAY & Vascular smooth muscle contraction & 8 & 2.732 & 0.026 & 0.433 \\
\hline KEGG_PATHWAY & Wnt signaling pathway & 9 & 2.476 & 0.028 & 0.405 \\
\hline KEGG_PATHWAY & Melanogenesis & 7 & 2.869 & 0.034 & 0.428 \\
\hline PANTHER_PATHWAY & TGF-beta signaling pathway & 10 & 2.080 & 0.046 & 0.876 \\
\hline KEGG_PATHWAY & Ubiquitin mediated proteolysis & 8 & 2.411 & 0.046 & 0.496 \\
\hline PANTHER_PATHWAY & Endogenous_cannabinoid_signaling & 4 & 4.832 & 0.047 & 0.757 \\
\hline PANTHER_PATHWAY & PDGF signaling pathway & 11 & 1.930 & 0.052 & 0.698 \\
\hline KEGG_PATHWAY & Glycerophospholipid metabolism & 5 & 3.059 & 0.078 & 0.654 \\
\hline PANTHER_PATHWAY & Endothelin signaling pathway & 7 & 2.290 & 0.080 & 0.772 \\
\hline PANTHER_PATHWAY & Notch signaling pathway & 5 & 2.963 & 0.084 & 0.727 \\
\hline PANTHER_PATHWAY & Metabotropic glutamate receptor group II pathway & 5 & 2.908 & 0.088 & 0.691 \\
\hline KEGG_PATHWAY & Neurotrophin signaling pathway & 7 & 2.207 & 0.095 & 0.692 \\
\hline PANTHER_PATHWAY & lonotropic glutamate receptor pathway & 5 & 2.804 & 0.098 & 0.682 \\
\hline KEGG_PATHWAY & N-Glycan biosynthesis & 4 & 3.564 & 0.100 & 0.679 \\
\hline
\end{tabular}




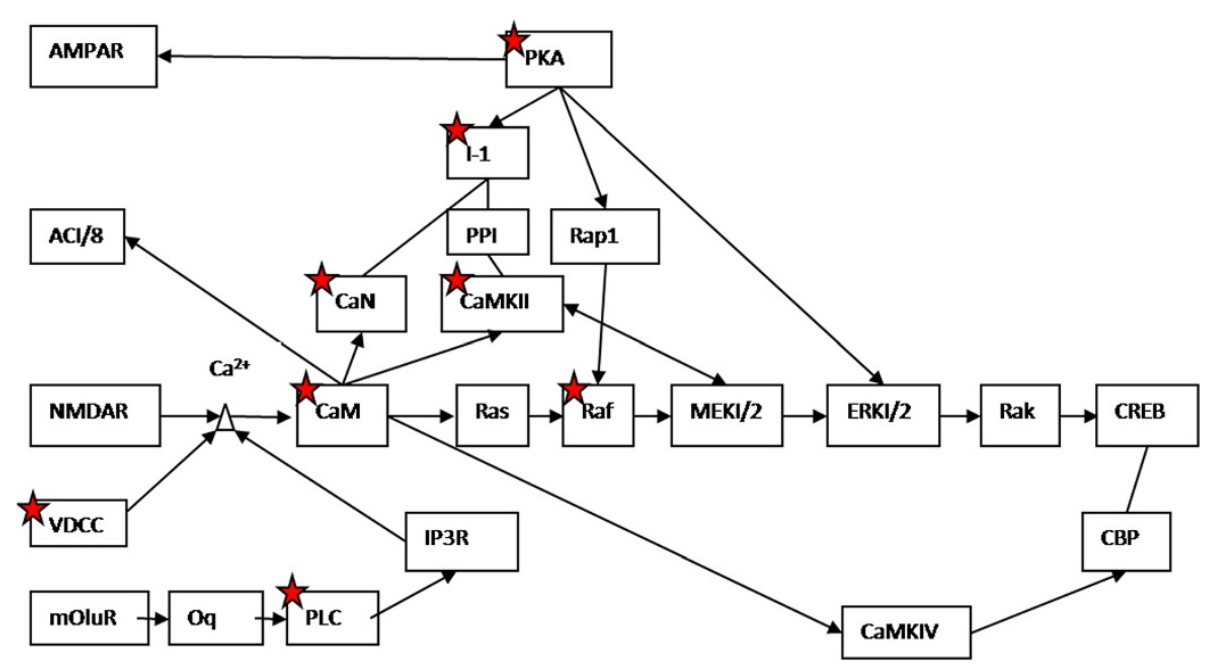

Figure 3 The 9 relative genes marked with red stars: Ppp1r1a(l-1), Ppp3r1(CaN), Raf1(Raf), Camk2b(CaMKII), Ppp3ca(CaN), Prkacb(PKA), Cacna1c(VDCC), PIcb1(PLC), and Calm2(CaM) in the most significant identified pathway, i.e., long-term potentiation.

CpG-rich regions of DNA are known as CpG islands (CGIs), and most CGIs remain unmethylated [48]. Moreover, approximately $60 \%$ of mammalian genes have CGI promoters, and methylated CGIs play an important role in gene silencing during processing [49]. The bestknown producer of epigenesis, DNA methylation, plays an important role in regulating gene expression to preserve local activity states [50]. Epigenesis is defined as heritable changes in gene expression that are not accompanied by changes in DNA sequence [51]. Thus, to reflect the DNA methylation landscape and distribution, we measured the methylation level in different regions of the genome. To gain more insight into whether the changes caused by methylation were present on the gene expression level, we performed comparisons between our MSCC data and the gene expression data (GDS1490). All our results were in accordance with the theoretical basic characteristics of DNA methylation modification in mammals, which confirmed the accuracy of our experiment.

It should be noted that when we used our criteria $(\triangle \mathrm{MSCC}>25 \%)$ to screen out differential genes in the normal and famine groups, no genes were selected in the hippocampus, while 500 distinct genes were revealed in the thalamus. This may due to the selected CCGG methylated level in the hippocampus, which was much lower than that in the thalamus. Thus, a methylation level of $>25 \%$ was difficult to achieve in the hippocampus. In this regard, further study of the hippocampus, which has vital roles in brain development, cognition, learning, and memory [52], would provide valuable information.

In the thalamus, the most significant identified relative pathway was long-term potentiation. It is a major form of long-lasting synaptic plasticity in the mammalian brain, which occurs by increasing synaptic strength, and is involved in information storage, and therefore, in learning and memory [53]. Ppp1r1a, Ppp3r1, Raf1, Camk2b, Ppp3ca, Prkacb, Cacna1c, Plcb1, and Calm2 were the filtered genes in this pathway from our study. These genes are critically involved in neuronal formation and development. Among the 9 genes, $C a m k 2 b$ plays important roles in brain synaptic plasticity [54]. Ppp3ca is a tumor suppressor gene that functions in Alzheimer's disease [25,26]. Prkacb is a protein kinase and is related to Alzheimer's disease [16]. Plcb1 is of critical importance in codifying neurotransmitter receptors and is associated with schizophrenia [46,47]. It is particularly noteworthy that the calcium channel, voltage-dependent, L-type, alpha $1 \mathrm{C}$ subunit (Cacna1c) gene contributes to many psychiatric disorders [55,56], specifically schizophrenia [40-42] and bipolar disorder [43-45].

Our study considered the global DNA methylation status of the thalamus and the hippocampus and provides a DNA methylation landscape of these two brain regions after they were modified by malnutrition. It also implicates DNA modification as an effective epigenetic regulator in postnatal brain maturation. Our data also indicate that malnutrition in postnatal individuals may increase the risk of developing psychiatric disorders such as Alzheimer's disease, schizophrenia and bipolar disorder. Nonetheless, we believe that much more research on the functional verification of the related genes is necessary to obtain a better understanding of the pathogenesis of malnutrition.

\section{Conclusions}

In this study, the thalamus and the hippocampus had different global DNA methylation statuses in postnatal 
malnourished mice and normal mice. Discriminable variations related to neuronal development and psychiatric disorders were also observed in the thalamus. Pathway analyses of the corresponding genes highlighted changes for 9 genes related to long-term potentiation (5.3-fold enrichment, $\mathrm{P}=0.033$ ). Our findings may help to differentiate the genome-wide DNA methylation status of different brain regions, and the results also indicate that postnatal malnutrition may increase the risk of psychiatric disorders.

\section{Additional files}

\section{Additional file 1: Supplementary materials.}

Additional file 2: Table S1. MSCC results of the thalamus for all MSCC $30+$ sites.

Additional file 3: Table S2. MSCC results of the hippocampus for all MSCC 30+ sites.

Additional file 4: Table S3. Selected 500 distinctive genes in the thalamus.

\section{Abbreviations}

5mC: 5-methylcytosine; NGS: Next-generation sequencing; MSCC: Methylsensitive cut counting; SLAC: Shanghai Laboratory Animal Co. Ltd; RFU: Relative fluorescence units; DMRs: Different methylated regions; $\triangle M S C C$ : Different levels of methylation changes; SD: Standard deviation; TSS: Transcription initiation site; LTP: Long-term potentiation; CGls: CpG islands; Cacna1c: Calcium channel, voltage-dependent, L-type, alpha 1C subunit gene.

\section{Competing interests}

The authors declare that they have no competing interests.

\section{Authors' contributions}

$\mathrm{LH}$ and $\mathrm{YL}$ supervised the experiment. DZZ and FTL designed the experimental protocol. XLW and FTL carried out the experiment. YL, XLW, DZZ, FTL, HZ, JYY, ZZ, DZ, YNW, LMT, LC, MYK, TW, GYF, XLQ, and JHS analyzed and discussed the experimental results. Finally, XLW, YL, and FTL wrote the manuscript. All authors read and approved the final manuscript.

\section{Acknowledgments}

This work was supported by the National Program on Key Basic Research Project of China (973 Program, 2011CB504000), the National Key Technology R\&D Program (2012BAI01B09), the Wu Jieping Medical Foundation (320.67001118), the National Natural Science Foundation of China (81121001), the National Natural Science Foundation of China (31200954), and China Postdoctoral Science Foundation-funded projects (2012 M510110, 2013 T60440).

\section{Author details}

${ }^{1}$ Institutes of Biomedical Sciences, Fudan University, Shanghai 200032, PR China. ${ }^{2}$ Bio-X Center, Key Laboratory for the Genetics of Developmental and Neuropsychiatric Disorders, Ministry of Education, Shanghai Jiao Tong University, Shanghai 200030, PR China. ${ }^{3}$ Institute for Nutritional Sciences, Shanghai Institutes for Biological Sciences, Chinese Academy of Sciences, Shanghai 200031, PR China. ${ }^{4}$ Luwan Branch of Ruijin Hospital, Shanghai Jiaotong University School of Medicine, Shanghai 200030, PR China. ${ }^{5}$ Key Laboratory of Molecular Medicine, The Ministry of Education, Department of Biochemistry and Molecular Biology, Fudan University Shanghai Medical College, 303 Ming Dao Building, 138 Yi Xue Yuan Road, Shanghai 200032, PR China. ${ }^{6}$ Bio-X Institute, Shanghai Jiao Tong University, Small White House, 1954 Hua Shan Road, Shanghai 200030, PR China.
}

Received: 13 June 2013 Accepted: 11 February 2014

Published: 20 February 2014

\section{References}

1. Alamy M, Bengelloun WA: Malnutrition and brain development: an analysis of the effects of inadequate diet during different stages of life in rat. Neurosci Biobehav Rev 2012, 36(6):1463-1480.

2. Morgane PJ, Austin-LaFrance R, Bronzino J, Tonkiss J, Diaz-Cintra S, Cintra L, Kemper T, Galler JR: Prenatal malnutrition and development of the brain Neurosci Biobehav Rev 1993, 17(1):91-128.

3. Black RE, Allen LH, Bhutta ZA, Caulfield LE, de Onis M, Ezzati M, Mathers C, Rivera J: Maternal and child undernutrition: global and regional exposures and health consequences. Lancet 2008, 371(9608):243-260.

4. Bergman $\mathrm{Y}, \mathrm{Cedar} \mathrm{H}$ : DNA methylation dynamics in health and disease. Nat Struct Mol Biol 2013, 20(3):274-281.

5. Weber M, Hellmann I, Stadler MB, Ramos L, Paabo S, Rebhan M, Schubeler $D$ : Distribution, silencing potential and evolutionary impact of promote DNA methylation in the human genome. Nat Genet 2007, 39(4):457-466

6. Niwa M, Jaaro-Peled H, Tankou S, Seshadri S, Hikida T, Matsumoto Y, Cascella NG, Kano S, Ozaki N, Nabeshima T, Sawa A: Adolescent stress-induced epigenetic control of dopaminergic neurons via glucocorticoids. Science 2013, 339(6117):335-339.

7. Ball MP, Li JB, Gao Y, Lee JH, LeProust EM, Park IH, Xie B, Daley GQ, Church GM: Targeted and genome-scale strategies reveal gene-body methylation signatures in human cells. Nat Biotechnol 2009, 27(4):361-368.

8. Guo JU, Ma DK, Mo H, Ball MP, Jang MH, Bonaguidi MA, Balazer JA, Eaves HL, Xie B, Ford E, Zhang K, Ming GL, Gao Y, Song H: Neuronal activity modifies the DNA methylation landscape in the adult brain. Nature neuroscience 2011, 14(10):1345-1351.

9. Gabory A, Attig L, Junien C: Developmental programming and epigenetics. Am J Clin Nutr 2011, 94(6 Suppl):1943S-1952S.

10. Shen Q, Li X, Qiu Y, Su M, Liu Y, Li H, Wang X, Zou X, Yan C, Yu L, Li S, Wan C, He L, Jia W: Metabonomic and metallomic profiling in the amniotic fluid of malnourished pregnant rats. Journal of proteome research 2008, 7(5):2151-2157.

11. da Huang W, Sherman BT, Lempicki RA: Systematic and integrative analysis of large gene lists using DAVID bioinformatics resources. Nat Protoc 2009, 4(1):44-57.

12. Jones PA: Functions of DNA methylation: islands, start sites, gene bodies and beyond. Nat Rev Genet 2012, 13(7):484-492.

13. Bird A: DNA methylation patterns and epigenetic memory. Genes Dev 2002, 16(1):6-21

14. Suzuki MM, Bird A: DNA methylation landscapes: provocative insights from epigenomics. Nat Rev Genet 2008, 9(6):465-476.

15. Holliday R: The inheritance of epigenetic defects. Science 1987, 238 (4824):163-170.

16. Fox MD, Raichle ME: Spontaneous fluctuations in brain activity observed with functional magnetic resonance imaging. Nat Rev Neurosci 2007, 8(9):700-711.

17. Yasuda H, Barth AL, Stellwagen D, Malenka RC: A developmental switch in the signaling cascades for LTP induction. Nat Neurosci 2003, 6(1):15-16.

18. Borgesius NZ, van Woerden GM, Buitendijk GH, Keijzer N, Jaarsma D, Hoogenraad CC, Elgersma Y: betaCaMKII plays a nonenzymatic role in hippocampal synaptic plasticity and learning by targeting alphaCaMKII to synapses. J Neurosci 2011, 31(28):10141-10148.

19. Chiocco MJ, Zhu X, Walther D, Pletnikova O, Troncoso JC, Uhl GR, Liu QR: Fine mapping of calcineurin (PPP3CA) gene reveals novel alternative splicing patterns, association of $5^{\prime}$ UTR trinucleotide repeat with addiction vulnerability, and differential isoform expression in Alzheimer's disease. Subst Use Misuse 2010, 45(11):1809-1826.

20. Lloret A, Badia MC, Giraldo E, Ermak G, Alonso MD, Pallardo FV, Davies KJ Vina J: Amyloid-beta toxicity and tau hyperphosphorylation are linked via RCAN1 in Alzheimer's disease. J Alzheimers Dis 2011, 27(4):701-709.

21. Vazquez-Higuera JL, Mateo I, Sanchez-Juan P, Rodriguez-Rodriguez E, Pozueta A, Calero M, Dobato JL, Frank-Garcia A, Valdivieso F, Berciano J, Bullido MJ, Combarros O: Genetic variation in the tau kinases pathway may modify the risk and age at onset of Alzheimer's disease. Journal of Alzheimer's disease: JAD 2011, 27(2):291-297.

22. Girirajan S, Dennis MY, Baker C, Malig M, Coe BP, Campbell CD, Mark K, Vu TH, Alkan C, Cheng Z, Biesecker LG, Bernier R, Eichler EE: Refinement and discovery of new hotspots of copy-number variation associated with autism spectrum disorder. American journal of human genetics 2013, 92(2):221-237.

23. Lo Vasco VR, Cardinale G, Polonia P: Deletion of PLCB1 gene in schizophrenia-affected patients. J Cell Mol Med 2012, 16(4):844-851. 
24. Moskvina V, Craddock N, Holmans P, Nikolov I, Pahwa JS, Green E, Owen MJ, O'Donovan MC: Gene-wide analyses of genome-wide association data sets: evidence for multiple common risk alleles for schizophrenia and bipolar disorder and for overlap in genetic risk. Mol Psychiatry 2009, 14(3):252-260.

25. Smoller JW, Craddock N, Kendler K, Lee PH, Neale BM, Nurnberger Jl, Ripke S, Santangelo S, Sullivan PF: Identification of risk loci with shared effects on five major psychiatric disorders: a genome-wide analysis. Lancet 2013, 381(9875):1371-1379.

26. Schizophrenia Psychiatric Genome-Wide Association Study C: Genome-wide association study identifies five new schizophrenia loci. Nat Genet 2011, 43(10):969-976.

27. Hamshere ML, Walters JT, Smith R, Richards AL, Green E, Grozeva D, Jones I, Forty L, Jones L, Gordon-Smith K, Riley B, O'Neill FA, Kendler KS, Sklar P, Purcell S, Kranz J, Schizophrenia Psychiatric Genome-wide Association Study Consortium, Wellcome Trust Case Control Consortium+, Wellcome Trust Case Control Consortium 2, Morris D, Gill M, Holmans P, Craddock N, Corvin A, Owen MJ, O'Donovan MC: Genome-wide significant associations in schizophrenia to ITIH3/4, CACNA1C and SDCCAG8, and extensive replication of associations reported by the Schizophrenia PGC. Molecular psychiatry 2013, 18(6):708-712.

28. Nyegaard M, Demontis D, Foldager L, Hedemand A, Flint TJ, Sorensen KM, Andersen PS, Nordentoft M, Werge T, Pedersen CB, Hougaard DM, Mortensen PB, Mors O, Borglum AD: CACNA1C (rs1006737) is associated with schizophrenia. Molecular psychiatry 2010, 15(2):119-121.

29. Ferreira MA, O'Donovan MC, Meng YA, Jones IR, Ruderfer DM, Jones L, Fan J, Kirov G, Perlis RH, Green EK, Smoller JW, Grozeva D, Stone J, Nikolov I, Chambert K, Hamshere ML, Nimgaonkar VL, Moskvina V, Thase ME, Caesar S, Sachs GS, Franklin J, Gordon-Smith K, Ardlie KG, Gabriel SB, Fraser C, Blumenstiel B, Defelice M, Breen G, Gill M, et al: Collaborative genome-wide association analysis supports a role for ANK3 and CACNA1C in bipolar disorder. Nature genetics 2008, 40(9):1056-1058.

30. Sklar P, Smoller JW, Fan J, Ferreira MA, Perlis RH, Chambert K, Nimgaonkar VL, McQueen MB, Faraone SV, Kirby A, de Bakker PI, Ogdie MN, Thase ME, Sachs GS, Todd-Brown K, Gabriel SB, Sougnez C, Gates C, Blumenstiel B, Defelice M, Ardlie KG, Franklin J, Muir WJ, McGhee KA, MacIntyre DJ, McLean A, VanBeck M, McQuillin A, Bass NJ, Robinson M, et al: Whole-genome association study of bipolar disorder. Molecular psychiatry 2008, 13(6):558-569.

31. Jogia J, Ruberto G, Lelli-Chiesa G, Vassos E, Maieru M, Tatarelli R, Girardi P, Collier D, Frangou S: The impact of the CACNA1C gene polymorphism on frontolimbic function in bipolar disorder. Mol Psychiatry 2011, 16(11):1070-1071.

32. Simons CJ, van Winkel R: Intermediate Phenotype Analysis of Patients, Unaffected Siblings, and Healthy Controls Identifies VMAT2 as a Candidate Gene for Psychotic Disorder and Neurocognition. Schizophr bulletin 2013, 39(4):848-856.

33. Villemagne VL, Okamura N, Pejoska S, Drago J, Mulligan RS, Chetelat G, Ackermann U, O'Keefe G, Jones G, Gong S, Tochon-Danguy H, Kung HF, Masters CL, Skovronsky DM, Rowe CC: In vivo assessment of vesicular monoamine transporter type 2 in dementia with lewy bodies and Alzheimer disease. Archives of neurology 2011, 68(7):905-912.

34. Kotagal V, Albin RL, Muller ML, Koeppe RA, Chervin RD, Frey KA, Bohnen NI: Symptoms of rapid eye movement sleep behavior disorder are associated with cholinergic denervation in Parkinson disease. Ann Neurol 2012, 71(4):560-568

35. Houlihan LM, Christoforou A, Arbuckle MI, Torrance HS, Anderson SM, Muir WJ, Porteous DJ, Blackwood DH, Evans KL: A case-control association study and family-based expression analysis of the bipolar disorder candidate gene PI4K2B. J Psychiatr Res 2009, 43(16):1272-1277.

36. Pun FW, Zhao C, Lo WS, Ng SK, Tsang SY, Nimgaonkar V, Chung WS, Ungvari GS, Xue H: Imprinting in the schizophrenia candidate gene GABRB2 encoding GABA(A) receptor beta(2) subunit. Mol Psychiatry 2011, 16(5):557-568.

37. Zhang W, Wang PJ, Li MH, Gao XL, Gu GJ, Shao ZH: 1 H-MRS can monitor metabolites changes of lateral intraventricular BDNF infusion into a mouse model of Alzheimer's disease in vivo. Neuroscience 2013, 245C:40-49.

38. Ranjbar E, Shams J, Sabetkasaei M, MS M, Rashidkhani B, Mostafavi A, Bornak E, Nasrollahzadeh J: Effects of zinc supplementation on efficacy of antidepressant therapy, inflammatory cytokines, and brain-derived neurotrophic factor in patients with major depression. Nutr Neurosci 2014, 17(2):65-71.

39. Nakatani $\mathrm{N}$, Hattori $\mathrm{E}$, Ohnishi T, Dean B, Iwayama Y, Matsumoto I, Kato T, Osumi N, Higuchi T, Niwa S, Yoshikawa T: Genome-wide expression analysis detects eight genes with robust alterations specific to bipolar I disorder: relevance to neuronal network perturbation. Human molecular genetics 2006, 15(12):1949-1962.

40. Muller $U$, Winter $P$, Graeber MB: A presenilin 1 mutation in the first case of Alzheimer's disease. Lancet Neurol 2013, 12(2):129-130.

41. Deng X, Takaki H, Wang L, Kuroki T, Nakahara T, Hashimoto K, Ninomiya H, Arinami T, Inada T, Ujike H, Itokawa M, Tochigi M, Watanabe $Y$, Someya T, Kunugi $H$, Iwata N, Ozaki N, Shibata $H$, Fukumaki Y: Positive association of phencyclidine-responsive genes, PDE4A and PLAT, with schizophrenia. Am J Med Genet B Neuropsychiatr Genet 2011, 156B(7):850-858.

42. Fatemi SH, Reutiman TJ, Folsom TD, Lee S: Phosphodiesterase-4A expression is reduced in cerebella of patients with bipolar disorder. Psychiatr Genet 2008, 18(6):282-288.

43. Mikhail FM, Lose EJ, Robin NH, Descartes MD, Rutledge KD, Rutledge SL, Korf BR, Carroll AJ: Clinically relevant single gene or intragenic deletions encompassing critical neurodevelopmental genes in patients with developmental delay, mental retardation, and/or autism spectrum disorders. Am J Med Genet A 2011, 155A(10):2386-2396.

44. Bangash MA, Park JM, Melnikova T, Wang D, Jeon SK, Lee D, Syeda S, Kim J, Kouser M, Schwartz J, Cui Y, Zhao X, Speed HE, Kee SE, Tu JC, Hu J, Petralia RS, Linden DJ, Powell CM, Savonenko A, Xiao B, Worley PF: Retraction notice to: Enhancedpolyubiquitination of Shank3 and NMDA receptor in a mouse model of autism. Cell 2013, 152(1-2):367.

45. Herbert MR: SHANK3, the synapse, and autism. N Engl J Med 2011, 365 (2):173-175

46. Denayer A, Van Esch H, de Ravel T, Frijns JP, Van Buggenhout G, Vogels A, Devriendt K, Geutjens J, Thiry P, Swillen A: Neuropsychopathology in 7 Patients with the 22q13 Deletion Syndrome: Presence of Bipolar Disorder and Progressive Loss of Skills. Molecular syndromology 2012, 3(1):14-20.

47. Tan L, Yu JT, Zhang W, Wu ZC, Zhang Q, Liu QY, Wang W, Wang HF, Ma XY, Cui WZ: Association of GWAS-linked loci with late-onset Alzheimer's disease in a northern Han Chinese population. Alzheimers Dement 2013, 9(5):546-553.

48. Yu JT, Ma XY, Wang YL, Sun L, Tan L, Hu N, Tan L: Genetic variation in Clusterin gene and Alzheimer's disease risk in Han Chinese. Neurobiol Aging 2013, 34(7):1921. e1917-1923.

49. Dieset I, Djurovic S, Tesli M, Hope S, Mattingsdal M, Michelsen A, Joa I, Larsen TK, Agartz I, Melle I, Rossberg Jl, Aukrust P, Andreassen OA, Ueland T: Up-regulation of NOTCH4 gene expression in bipolar disorder. Am J Psychiatry 2012, 169(12):1292-1300.

50. Shayevitz C, Cohen OS, Faraone SV, Glatt SJ: A re-review of the association between the NOTCH4 locus and schizophrenia. Am J Med Genet B Neuropsychiatr Genet 2012, 159B(5):477-483.

51. Meltzer HY, Brennan MD, Woodward ND, Jayathilake K: Association of Sult4A1 SNPs with psychopathology and cognition in patients with schizophrenia or schizoaffective disorder. Schizophr Res 2008, 106(2-3):258-264.

52. Anderson LR, Betarbet R, Gearing M, Gulcher J, Hicks AA, Stefansson K, Lah JJ, Levey Al: PARK10 candidate RNF11 is expressed by vulnerable neurons and localizes to Lewy bodies in Parkinson disease brain. J Neuropathol Exp Neurol 2007, 66(10):955-964.

53. Sullivan PF, de Geus EJ, Willemsen G, James MR, Smit JH, Zandbelt T, Arolt $V_{\text {, }}$ Baune BT, Blackwood D, Cichon S, Coventry WL, Domschke K, Farmer A, Fava M, Gordon SD, He Q, Heath AC, Heutink P, Holsboer F, Hoogendijk WJ, Hottenga JJ, Hu Y, Kohli M, Lin D, Lucae S, Macintyre DJ, Maier W, McGhee KA, McGuffin P, Montgomery GW, et al: Genome-wide association for major depressive disorder: a possible role for the presynaptic protein piccolo. Molecular psychiatry 2009, 14(4):359-375.

54. Choi KH, Higgs BW, Wendland JR, Song J, McMahon FJ, Webster MJ: Gene expression and genetic variation data implicate PCLO in bipolar disorder. Biol Psychiatry 2011, 69(4):353-359.

55. Zheng Y, Wang Q, Xiao B, Lu Q, Wang Y, Wang X: Involvement of receptor tyrosine kinase Tyro3 in amyloidogenic APP processing and beta-amyloid deposition in Alzheimer's disease models. PLoS One 2012, 7(6):e39035.

56. Kang HJ, Voleti B, Hajszan T, Rajkowska G, Stockmeier CA, Licznerski P, Lepack A, Majik MS, Jeong LS, Banasr M, Son H, Duman RS: Decreased expression of synapse-related genes and loss of synapses in major depressive disorder. Nature medicine 2012, 18(9):1413-1417.

doi:10.1186/1471-2202-15-31

Cite this article as: Weng et al.: DNA methylation profiling in the thalamus and hippocampus of postnatal malnourished mice, including effects related to long-term potentiation. BMC Neuroscience 2014 15:31. 